\title{
Envisioning Higher Education for the Future
}

\author{
Henning Jensen-Pennington
}

\section{Introduction-International Cooperation and the Significance of Integration}

In a constantly changing global society, higher education faces threats, challenges and opportunities that are not static, but are constantly evolving and transforming. Higher education institutions are prone to appreciate universal values, traditions and stability, which is specific and extremely relevant assets that help explain the profound roots they have put down across many cultures and highlight their enduring contribution to societal development in almost all dimensions, from material production and scientific innovation to artistic creativity and critical thinking about the surrounding world.

It is important to take note of the fact that these prominent, and unquestionably important, aspects of higher education also impair their capacity to anticipate and react critically — not adaptively in the sense of passive adjustment - to current and future challenges. In order to face dynamic new circumstances, higher education institutions, and their regional and international organizations, need to tenaciously rethink their contribution and position in a constantly changing world.

This is indeed a complex operation; for one, because the fabric of higher education is interwoven with multiple and diverse interests and expectations, both internal and external. Moreover, institutions are frequently pressured by political environments that are not necessarily attuned to education in general, and to science and knowledge in particular. It is essential for higher education to be fully aware of this complexity in order to discern how best to negotiate its way through the mesmerizing diversity of the present while remaining fully pertinent and relevant.

Universities play a fundamental role in the empowerment of individuals and societies. It is frequently argued that it is necessary to adhere to evaluation and accred-

\footnotetext{
H. Jensen-Pennington $(\varangle)$

Universidad de Costa Rica, San José, Costa Rica

e-mail: hjensenp@gmail.com 
itation processes to ensure quality and academic relevance. That is perhaps selfevident. But the emphasis placed on these processes in the last decades, including the proliferation of rankings, has led to a narrative that has undervalued-or at least disregarded - the importance of long-term planning, internal and international dialogue, and negotiation. More importantly, such a narrative pays insufficient heed to higher education's commitment to society. I do not refer to the latter in abstract terms, nor in the sense of vertical impacts, but as a process embedded in a reciprocal and intertwined learning experience that enriches both universities and societies.

In many countries of the world, universities are central and emblematic: much to the pride of nations, they play a central role in fostering the rule of law, in both social and democratic terms. In Latin America, for instance, public universities have been significant for the promotion of social mobility, a means for strengthening equality, combating poverty, and generating opportunities.

No country is immune to the erosion of its democratic institutional framework, and concessions to its academic freedom. Universities can mitigate these negative outcomes by participating in consensual alliances with similarly inspired civil society groups with national and regional agendas aimed at achieving prosperity and preserving the common good, which in turn are explicit values of the academic ethos.

\section{Promotion of Regional and International Integration Through Academic Mobility of Teachers, Students and Administrative Staff}

Universities, as institutions that cultivate science, technology, and culture, are part of a context of wide internationality, in which cross-transmission of knowledge and experiences predominates.

Knowledge - as we know-is currently more widely distributed in the world than ever before. Advanced universities are open to multidirectional mobility of faculty and students, carry out high-level shared projects, jointly address highly complex issues, and nurture cultural diversity via mutually-beneficial, respectful partnerships.

A comprehensive university must consolidate its position in such academic scenarios, now more extensively than ever, by forming academic alliances through broad and flexible networks. These will allow university groups to place themselves on the stage of science and technology, as well as of art and the humanities at regional and global scales. 


\section{Internationalization by Strengthening the Internal Capacity for International Cooperation}

Universities must meet the challenge of visualizing internationalization as an integral tool of organizational restructuring, of management models and should be part of the social responsibility of our institutions. This includes the design of effective policies in institutional terms, sponsoring greater participation for all sectors involved, such as academics, students, and administrative staff. But also with other external stakeholders or social forces with whom alliances can become fertile endeavours, not only to obtain resources or stimulating funding but to change mentalities, ways of perceiving and thinking, reactivating debate on the moral sense of internationalization.

The idea of structuring and applying an endogenous internationalization model bears many opportunities: it opens up possibilities to devise programmes focused on pragmatic, relevant or comprehensive internationalization, in line with priorities of institutional development projects, with demands coming from the receiving environments and interests of different stakeholders, in its literal meaning of this noun: an individual or groups of persons that are invested in - that is, endorse-the goals and values of higher education.

\section{Creation of an Ecosystem That Promotes Scientific and Technological Development}

The transfer of knowledge should contribute to the common good, foster social cohesion and production, promote the well-being of groups and communities, with a special focus on the most vulnerable.

The university must stimulate and take advantage of synergies and interactions with other national institutions and thus forge effective policies in the transfer of knowledge to society.

A more fertile and intense encounter between university and society can be achieved through stronger interlinkages of universities with their immediate social, political and economic environment and the needs of the population therein.

In these environments - and this may also apply to highly developed countriesthere are often issues such as health, food production and security, housing, energy, and water quality needs, among others. Many solutions require public intervention. But, solutions can often be facilitated with the help of advanced knowledge: universities can provide training and associated learning, carry out scientific and technological research, give advice to local governments.

We must not forget that the local dimension is very relevant to sustainable development strategies and plays a significant role in knowledge construction processes. This demands an integral vision of academic life so that interdisciplinary efforts and cross-fertilization between disciplines are facilitated with active student participation. 
Integration of the substantial activities of a university: teaching, research, and social responsibility and commitment, is a goal that is not easy to achieve. On the contrary, systematic efforts and coordinated programmes are required so that students receive updated knowledge, learn advanced research processes and, at the same time, together with faculty members, put that knowledge at the service of society. The proverbial wisdom that educators have to be educated is perhaps nowhere more appropriate than in this context: educate educators to generate, share, and implement knowledge, and its innovative iterations. No university purely dedicated to teaching can even begin to grasp the complexity of this, which becomes even bigger if we take into account the diversity of the social sectors involved and the speed with which knowledge evolves in all areas and disciplines.

That is why every university should place special emphasis on the quality of its teachers and students. To this end, the planning of generational replacement and the refinement of the processes and mechanisms of hiring academic personnel is essential. In addition, continuous training of administrative staff must be integrated into this mechanism in a complementary way. As part of this process, it is necessary to strengthen the institution's graduate programmes and direct academic policies towards a system of merit with competitive salaries within national and international frameworks.

Given the accelerated changes in knowledge, actions that contribute to greater flexibility and curricular versatility are required, with the creation of new programmes, integration of, amongst others, student mobility between different disciplines. In the case of those universities with regional representation, horizontal regionalization models must be promoted as they marry regional pertinence with national relevance. These models must be developed according to the needs of the country in general and of the regions in particular.

\section{Horizontal Creation of Programmes Which Include Student and Community Participation, and Recognition of the Dignity of Diversity (of Knowledge)}

By deepening horizontal processes, at all academic levels, a systemic, unitary, comprehensive and efficient institutional concept can be strengthened. The organic articulation of university development, which can be imagined as intertwined threads of academic initiatives, connected with and permeating the functioning of management, will contribute, without a doubt, to the social inclusion of wider sections of the population.

We live in exceptional circumstances and times, characterized by increasing epistemophobia and the predominance of a sort of logic of suspicion and disregard that undermines the legitimacy of systematic knowledge. Universities are, after all, cultural institutions - and the promoters of precise knowledge and critical appraisaland as such, must seek new alliances. These will inevitably embrace a new way of 
dealing with relevant public issues. But, the university that seeks those new alliances has to do so in a context of a new Enlightenment, a non-Eurocentric effort to include diverse knowledge systems and cultural practices.

Each member of the university community must experience how these institutions live up to their aspirations, grant them new points of view, and open opportunities and possibilities for development. Through something as obvious (yet often stifled) as the guarantee of fundamental rights in each institution, and through the expansion of services that have not been traditionally addressed, greater university cohesion can be created. Similarly, it is essential to generate more reflection on the type of services sought in public institutions, and that the State must warrant.

The knowledge generated in higher education should ideally impregnate the entire society, but that permeability must be bi-directional: the university must learn from the collective knowledge of all social agents.

\section{Contribution to the Achievement of the Sustainable Development Goals (SDGs)}

In the move towards sustainable development, scientific, technological and innovation, together with training, are undoubtedly fundamental. In many regions of the world, universities have extensive scientific and technological research capabilities, as well as human talent. Through its interactions with other social actors, transforming itself, and influencing public policies, higher education helps us to fight inequalities, improve the environment, and move forward towards development and remove barriers by resorting to knowledge, science, technology, and innovation.

Higher education institutions are aware of the demand for knowledge linked to the objectives of the 2030 Agenda, and of the important role they play in achieving them. The link between higher education and territorial development is one which promises to connect higher education to society and thus meet the demands of the SDGs.

The prevailing hegemonic development model is environmentally, economically, and socially unsustainable, and it is becoming increasingly clear that humanity needs to move towards a new model of development and a different concept of progress. Indeed, the bathe cry of the SDGs is to summon knowledge, education, science, technology and innovation to solve the problems addressed by the 2030 Agenda, and are precisely areas that higher education institutions directly address.

The Economic Commission for Latin America and the Caribbean (CEPAL, in Spanish) has defined a set of priorities that, fundamentally, connect the SDGs with core functions of higher education:

1. The centrality of equality. In addressing the issue from Latin America and the Caribbean, the most unequal region on the planet, CEPAL insists that equality is a key issue. The current production, dissemination, and use of knowledge are closely linked to inequality; 
2. Balanced integration of the three dimensions of development: economic, social and environmental;

3. A structural change that enables the incorporation of knowledge into production guarantees social inclusion and allows for progress on a low carbon-emission path through a large environmental impulse;

4. The advancement of technological innovation, the digital economy, and the information society;

5. Capacity building through quality education.

These challenges have emerged from the social capacities and weaknesses of Latin America, but they are not unique. Higher education institutions are called upon to actively engage in shaping global development plans; they must make sure that each contribution is made visible and addressed with the importance it deserves, and they must work toward successfully reaching the global development goals, ensuring equality among all inhabitants of the global village.

\section{Closing Remarks}

These are some of the challenges that the future poses. All of them must be seen in the context of complex and contradictory national, regional, and international realities. The leadership that universities worldwide have forged should be instrumental in promoting strong interaction with external social and political sectors, and this will benefit from a permanent process of dialogue and negotiation.

When facing new challenges, universities must not fall into complacency. On the contrary, they must be the living paradigm of scientific ethics and ethos regarding selfcriticism and demonstrate an openness to the contributions that come from beyond the campus. This dialogical attitude is elemental for social well-being and, as such, must become an integral part of the university.

Henning Jensen-Pennington is former Rector of Universidad de Costa Rica (2012-2020). Before that, he was Director of the Institute of Psychological Research, Dean of the School of Social Sciences, Director of Doctorate Studies of Society and Culture, and Research Vice-Rector at the same university. He has also been a consultant for the Pan American Health Organization and President of the Psychological Association of Costa Rica. From 2004 to 2011, he presided over the Foundation of the University of Costa Rica for Research. 
Open Access This chapter is licensed under the terms of the Creative Commons Attribution 4.0 International License (http://creativecommons.org/licenses/by/4.0/), which permits use, sharing, adaptation, distribution and reproduction in any medium or format, as long as you give appropriate credit to the original author(s) and the source, provide a link to the Creative Commons license and indicate if changes were made.

The images or other third party material in this chapter are included in the chapter's Creative Commons license, unless indicated otherwise in a credit line to the material. If material is not included in the chapter's Creative Commons license and your intended use is not permitted by statutory regulation or exceeds the permitted use, you will need to obtain permission directly from the copyright holder. 